\title{
High light stress triggers distinct proteomic responses in the marine diatom Thalassiosira pseudonana
}

\author{
Hong-Po Dong ${ }^{1,2+}$, Yue-Lei Dong ${ }^{1 \dagger}$, Lei Cui ${ }^{1}$, Srinivasan Balamurugan ${ }^{1}$, Jian Gao ${ }^{1}$, Song-Hui Lu ${ }^{1 *}$ and Tao Jiang ${ }^{1}$
}

\begin{abstract}
Background: Diatoms are able to acclimate to frequent and large light fluctuations in the surface ocean waters. However, the molecular mechanisms underlying these acclimation responses of diaotms remain elusive.

Results: In this study, we investigated the mechanism of high light protection in marine diatom Thalassiosira pseudonana using comparative proteomics in combination with biochemical analyses. Cells treated under high light $\left(800 \mu \mathrm{mol}\right.$ photons $\left.\mathrm{m}^{-2} \mathrm{~s}^{-1}\right)$ for $10 \mathrm{~h}$ were subjected to proteomic analysis. We observed that 143 proteins were differentially expressed under high light treatment. Light-harvesting complex proteins, ROS scavenging systems, photorespiration, lipid metabolism and some specific proteins might be involved in light protection and acclimation of diatoms. Non-photochemical quenching (NPQ) and relative electron transport rate could respond rapidly to varying light intensities. High-light treatment also resulted in increased diadinoxanthin + diatoxanthin content, decreased FV/Fm, increased triacylglycerol and altered fatty acid composition. Under HL stress, levels of C14:0 and C16:0 increased while C20:5 w3 decreased.
\end{abstract}

Conclusions: We demonstrate that T. pseudonana has efficient photoprotective mechanisms to deal with $\mathrm{HL}$ stress. De novo synthesis of Ddx/Dtx and lipid accumulation contribute to utilization of the excess energy. Our data will provide new clues for in-depth study of photoprotective mechanisms in diatoms.

Keywords: Thalassiosira pseudonana, iTRAQ labeling, Quantitative proteomics, Light protection

\section{Background}

Diatoms are unicellular, eukaryotic phytoplankton that account for approximately $40 \%$ of the marine primary productivity, which makes them indispensable for marine food webs [1]. Besides, they play a vital role in nutrient recycling and climate regulation [1]. In light of their ecological importance, the genomes of several diatom species have been sequenced [2], which greatly contributed to in-depth studies of diatom molecular biology. In the oceanic surface waters, diatoms are frequently exposed to drastic fluctuations in light intensity that can be harmful for photosynthesis and growth. For example, it is observed that in Big Island of Hawaii in July, maximum

\footnotetext{
*Correspondence: lusonghui1963@163.com

${ }^{\dagger}$ Equal contributors

${ }^{1}$ Research Center for Harmful Algae and Marine Biology, Key Laboratory of Eutrophication and Red Tide Prevention of Guangdong Higher Education Institutes, Jinan University, Guangzhou 510632, China

Full list of author information is available at the end of the article
}

photosynthetically active radiation (PAR) ranged from 0 to $1300 \mu \mathrm{mol}$ photons $\mathrm{m}^{-2} \mathrm{~s}^{-1}$ on a clear day at a depth of $3 \mathrm{~m}$ while it ranged from 0 to $700 \mu \mathrm{mol}$ photons $\mathrm{m}^{-2} \mathrm{~s}^{-1}$ on a cloudy summer day [3]. Under such unpredictable and uncontrollable conditions, diatoms evolve sophisticated cellular mechanisms to protect the photosynthetic apparatus, which may be one of the reasons for their ecological success [4].

A number of physiological photoprotective mechanisms have evolved in various photosynthetic organisms to regulate photosynthesis under rapid light fluctuations. These mechanisms include the photosystem II (PSII) and PSI electron cycles, the fast repair of D1 protein of the PSII reaction center, the state-transitions, changes in the efficiency of energy shift from the harvesting complex to the reaction center, and non-photochemical quenching (NPQ) induced by activation of the xanthophyll cycle (XC) $[5,6]$. Among these, the NPQ are of primary importance [7]. The XC constitutes the de-epoxidation of 
diadinoxanthin (Ddx) to diatoxanthin (Dtx) which is activated by the acidification of the thylakoid lumen resulting in accumulation of Dtx [7]. The levels of Ddx and Dtx were strongly affected by light intensity, and cells grown in high light (HL) almost doubled the pool size of XC pigments relative to cells grown in low light (LL) [8]. Silencing of the violaxanthin de-epoxidase gene in the diatom Phaeodactylum tricornutum resulted in reduced Dtx synthesis and NPQ, thus confirming the mechanistic model of the Dtx/NPQ relationship in diatoms [9]. In the ocean, XC and NPQ have shown to be the important features that might potentially influence niche adaptation of diatoms [10].

Molecular mechanisms underlying photoprotection in diatoms have been investigated in many studies. Eisenstadt and colleagues suggested that changes in the PSII core center play an important role in P. tricornutum during acclimation to varying light conditions [11]. Lhcx6 protein bound with Dtx could participate in heat dissipation of excess light energy under HL stress [12]. In $P$. tricornutum, D1 degradation rate as well as repair rate increased under HL exposure, suggesting the important role of D1 repair cycle in limiting photoinhibition [13]. The redox state of the PQ pool is considered to play a crucial role in the photosynthetic regulatory processes. A recent study revealed that high light acclimation in diatoms was triggered by the redox state of the plastoquinone pool [14]. More recently, chloroplast- localized death-specific protein (DSP1) was identified and its overexpression in T. pseudonana clone lines resulted in elevated cyclic electron flow (CEF) and expression of proteins involved in photosynthesis and carbon fixation [15]. However, these existing literatures have focused mainly on specific proteins rather than the whole algal proteome, therefore, the key genes and proteins involved in photoprotective responses to HL exposure in diatoms remain unknown.

"Omics" approaches are essential for reconstructing the metabolic pathways and regulatory networks responsible for light acclimation in diatoms. T. pseudonana is a centric diatom widely distributed throughout the world's oceans. Its available genomic information, in combination with the key roles it plays in marine food webs and global carbon cycling, made it become model organism for molecular ecological studies. Several proteomic studies have been conducted in T. pseudonana to investigate the effects of nitrogen starvation and benzoapyrene exposure $[16,17]$. A global regulation picture of the metabolic processes in response to nitrogen starvation was described, and some protein biomarkers were discovered when exposed to benzoapyrene. In addition, proteomic analysis in $T$. pseudonana under Fe limitation revealed that proteins involved in intracellular protein turnover pathways was increased, thus reducing demand for extracellular Fe [18]. In this study, we employ a proteomic approach based on isobaric tags for relative and absolute quantification (iTRAQ) labeling to examine the light protection mechanisms of $T$. pseudonana under excess light stress. This is the first proteomic study to demonstrate the protection strategies of a marine diatom to high light conditions experienced in the ocean. These data will provide new mechanistic insights into the responses of the marine diatom T. pseudonana to fluctuating light conditions from a proteomic perspective.

\section{Methods}

\section{Growth conditions}

Axenic T. pseudonana, obtained from the ProvasoliGuillard National Center for Marine Algae and Microbiota, was grown in artificial seawater supplemented with $\mathrm{f} / 2$ vitamins and inorganic nutrients [19]. Cultures were grown in growth chamber at $19{ }^{\circ} \mathrm{C}$ with irradiance of $30 \mu \mathrm{mol}$ photons $\mathrm{m}^{-2} \mathrm{~s}^{-1}$ (LL) and were kept in exponential growth phase for at least 4 weeks to ensure that all cells were acclimated. The illumination was provided by cool white fluorescent light with $12 / 12 \mathrm{~h}$ light/dark cycles. The growth rate was measured by monitoring in vivo fluorescence using a Turner Designs Model 10 Fluorometer (Turner Designs, CA, USA). For mediumlight (ML, $200 \mu \mathrm{mol}$ photons $\mathrm{m}^{-2} \mathrm{~s}^{-1}$ ) and high-light $\left(\mathrm{HL}, 800 \mu \mathrm{mol}\right.$ photons $\mathrm{m}^{-2} \mathrm{~s}^{-1}$ ) treatment, continuous light illumination was applied. The cells under LL conditions were divided into two parts. One part was exposed to $800 \mu \mathrm{mol}$ photons $\mathrm{m}^{-2} \mathrm{~s}^{-1}$ (HL) for $10 \mathrm{~h}$ for iTRAQ labeling, lipid and fatty acid analysis. The other part was kept under LL as a control. Samples for Fv/Fm, NPQ and pigment analysis were collected at time points $1,3,6,10$ and $12 \mathrm{~h}$ after transfer to ML or HL conditions. In a short-term experiment, cells were exposed to $1 \mathrm{~h}$ of ML or HL, followed by $1 \mathrm{~h}$ of LL recovery, with a subsequent $1 \mathrm{~h} \mathrm{ML}$ or HL treatment, for determination of relative electron transport rate (rETR) and NPQ. Experiments were performed in triplicate for each treated and control cultures.

\section{Chlorophyll fluorescence measurements}

The parameters $F v / F m$ (the maximum photosynthetic efficiency of PSII) and rETR were determined using a Phyto-PAM Phytoplankton Analyzer (Walz, Germany). For $F v / F m, 4 \mathrm{ml}$ of the culture was dark-acclimated for 15-20 min before taking a measurement. NPQ was calculated using the Stern-Volmer parameter as NPQ = $F m / F m^{\prime}-1$.

\section{Pigment analysis}

For pigment analysis, $15 \mathrm{ml}$ of culture was filtered using $\mathrm{GF} / \mathrm{F}$ filter and the filter was immediately frozen in liquid nitrogen, and stored at $-80{ }^{\circ} \mathrm{C}$ until analysis. Pigment 
quantitation was performed using an Agilent 1200 HPLC system (Agilent technologies, CA, USA) with a Symmetry C8 column $(4.6 \times 150 \mathrm{~mm})$ following a previous method [20].

\section{Lipid and fatty acid analysis}

For confocal microscopy analysis, cells were stained in the dark with Nile red at a final concentration of $1 \mu \mathrm{g} \mathrm{ml}^{-1}$ (from a stock of $0.1 \mathrm{mg} \mathrm{ml}^{-1}$ in acetone) and incubated in darkness, for $15 \mathrm{~min}$. Images of oil bodies were captured using a LSM 510 META laser-scanning confocal microscope (Zeiss, Jena, Germany) with excitation wavelength of $488 \mathrm{~nm}$ and emission wavelength of 560-615 nm.

The neutral lipid content was detected using Nile red dye in combination with flow cytometry as described previously [21].

Fatty acids were analyzed directly from liquid cultures as described previously [22]. Lipids were extracted and derivatized from liquid culture. Fatty acid methyl esters (FAMEs) were analyzed by gas chromatography-mass spectrometry (GC-MS) in Analytical and Testing Center of Jinan University. FAMEs were quantified against a standard curve from different concentrations of C19:0 and C21:0 standard mixtures (nonadecanoic acid and heneicosanoic acid). The internal C19:0 and C21:0 standards run with each sample were used for calculating the recovery of FAMEs.

\section{Total protein extraction and iTRAQ labeling}

Approximately $600-800 \mathrm{ml}$ cultures were centrifuged at $8000 \times \mathrm{g}$ for $10 \mathrm{~min}$ at $4{ }^{\circ} \mathrm{C}$. The supernatant was decanted, and cell pellets were lysed in rehydration buffer $(7 \mathrm{M}$ urea, $2 \mathrm{M}$ thiourea, $10 \mathrm{mM}$ dithiothreitol (DTT) and 4\% W/V CHAPS) with sonication in ice using a microprobe $(20 \%$ output, 20 to 30 cycles, $5 \mathrm{~s}$ each interrupted by $5 \mathrm{~s}$ of cooling). After centrifugation at $12,000 \times \mathrm{g}$ at $4{ }^{\circ} \mathrm{C}$, the supernatants were reduced and alkylated with $10 \mathrm{mM}$ DTT and $55 \mathrm{mM}$ iodoacetamide (final concentration), respectively. The proteins in the supernatants were precipitated by adding 4 times volume of $100 \%$ cold acetone at $-20{ }^{\circ} \mathrm{C}$ overnight, and the precipitates were resuspended in $0.8 \mathrm{M}$ urea and $0.5 \mathrm{M}$ tetraethylammonium bicarbonate (TEAB), $\mathrm{pH}$ 8.5. The protein concentration was measured using the Bradford method, thereafter digested with trypsin at $37{ }^{\circ} \mathrm{C}$ for $12 \mathrm{~h}$. The tryptic peptides were labeled by the 8-plex iTRAQ reagents (AB Sciex, CA, USA) following the manufacturer's protocol. After $2 \mathrm{~h}$ of labeling, the reaction solvents were evaporated by speed-vacuum, and the labeled peptides were dissolved in buffer A $\left(25 \mathrm{mM} \mathrm{NaH}_{2} \mathrm{PO}_{4}\right.$ in $25 \%$ acetonitrile, $\mathrm{pH} 2.7$ ) for the peptide fractionation.

Peptide fractionation by strong cation exchange (SCX) HPLC SCX chromatography was performed with a LC-20AB HPLC Pump system (Shimadzu, Kyoto, Japan). The
iTRAQ-labeled peptide mixtures were reconstituted with $4 \mathrm{ml}$ buffer A and loaded onto a $4.6 \times 250 \mathrm{~mm}$ Ultremex SCX column containing $5-\mu \mathrm{m}$ particles (Phenomenex, USA). The peptides were eluted at a flow rate of $1.0 \mathrm{ml} \mathrm{min}^{-1}$ using a gradient of buffer A for 10 min, 5-60\% buffer B (25 mM $\mathrm{NaH} 2 \mathrm{PO} 4,1 \mathrm{M} \mathrm{KCl}$ in 25\% acetonitrile, $\mathrm{pH} 2.7$ ) for $27 \mathrm{~min}$, and $60-100 \%$ buffer B for $1 \mathrm{~min}$. The system was then maintained at $100 \%$ buffer $B$ for 1 min before equilibrating with buffer $A$ for 10 min prior to the next injection. Elution was monitored by measuring the absorbance at $214 \mathrm{~nm}$, and fractions were collected every $1 \mathrm{~min}$ interval. The eluted peptides were pooled into 20 fractions, desalted with a Strata X C18 column (Phenomenex) and vacuum-dried.

\section{Peptide identification by nano RP HPLC and mass spectrometry}

Each fraction was resuspended in buffer C (5\% acetonitrile in $0.1 \%$ formic acid) and centrifuged at $20,000 \times \mathrm{g}$ for $10 \mathrm{~min}$. Ten microliters of supernatant was loaded on a LC-20 AD nanoHPLC (Shimadzu, Kyoto, Japan) by the autosampler onto a 2-cm C18 trap column. Then, the peptides were loaded onto a 10-cm analytical C18 column (inner diameter $75 \mu \mathrm{m}$ ), with the flow rate at $8 \mu \mathrm{min}^{-1}$ in $4 \mathrm{~min}$, and were eluted with the $35 \mathrm{~min}$ linear gradient starting from 2 to 35\% B (95\% acetonitrile in $0.1 \%$ formic acid) at $300 \mathrm{nl} \mathrm{min}{ }^{-1}$, followed by a $5 \mathrm{~min}$ linear gradient to $60 \% \mathrm{~B}$, which was followed by a $2 \mathrm{~min}$ linear gradient to $80 \% \mathrm{~B}$.

Data acquisition was performed with a TripleTOF 5600 System (AB Sciex, Concord, CAN). The mass spectrometer was operated with an RP greater than or equal to 30,000 FWHM for TOF MS scans. For informationdependent acquisition (IDA), survey scans were acquired in $250 \mathrm{~ms}$, and as many as 30 product ion scans were collected if exceeding a threshold of 120 counts per second (counts s${ }^{-1}$ ). Four time bins were summed for each scan at a pulser frequency value of $11 \mathrm{kHz}$ through monitoring of the $40 \mathrm{GHz}$ multichannel TDC detector.

\section{Peptide and protein identification}

The raw MS/MS data were converted into Mascot generic format (MGF), and the exported MGF files were searched by Mascot 2.3.02 (Matrix Science, London, UK) against the database with 24,591 predicted proteins in T. pseudonana downloaded from National Center for Biotechnology Information (NCBI) [23]. The search parameters were set as follows: tolerance of one missed cleavage of trypsin, oxidation $(\mathrm{M})$ for methionine as the variable modifications, and carbamidomethyl (C) for cysteine, iTRAQ8-plex (N-term), and iTRAQ8-plex (K) as fixed modifications. A mass tolerance of $0.05 \mathrm{Da}$ was permitted for intact peptide masses and 0.1 Da for fragmented ions. The charge states of peptides were 
set to +2 and +3 . Specifically, an automatic decoy database search was performed to estimate the false discovery rate (FDR) of peptides in Mascot by choosing the decoy checkbox in which a random sequence of database is generated. The FDR was $1.1 \%$. For peptide identification, only peptides at the $95 \%$ confidence interval $(P<0.05)$ by a Mascot probability analysis greater than "identity" were considered as confident.

\section{Quantitative data analysis for the ITRAQ labeling peptides} A unique protein with at least two unique peptides was qualified for further quantification data analysis. The quantitative protein ratios were weighted and normalized by the median ratio in Mascot. The peptide for quantification was automatically selected by Mascot to calculate the reporter peak area, error factor and $p$-value (default parameters in Mascot software package). The fold changes in protein abundance were defined as the median ratios of all significantly matched spectra with tag signals. Statistically significant variation $(P<0.05)$ and a ratio greater than 1.5 were used for cutoffs. The quantitation was performed at the peptide level following the procedures provided in http:// www.matrixscience.com/help/quant_statistics_help.html. The student's T-test was carried out using the Mascot software.

\section{Quantitative real-time PCR (qRT-PCR)}

RNA was extracted using Trizol (Invitrogen). An equal amount of RNA was used for all samples to be transcribed into complementary DNA (cDNA) using the AMV First Strand cDNA Synthesis Kit. The resulting cDNA was diluted 8-fold as the qRT-PCR template. Amplicons were quantified in qRT-PCR reactions with ABI SYBR Green PCR Master Mix (Applied Biosystems). Additionally, qRT-PCR was performed in a LightCycler 480 instrument by standard methods (Roche) as previously described [24]. The $2^{\triangle \triangle C T}$ method was used to estimate fold changes in gene expression, normalized to the endogenous control gene, actin [24]: Comparative relative expression $\left(2^{\Delta \Delta \mathrm{CT}}\right)=2^{-}\{[\mathrm{CT}(\mathrm{HL})-\mathrm{CT}(\mathrm{control})]-[\mathrm{CT}(\mathrm{LL})-$ $\mathrm{CT}($ control)]\}, where $\mathrm{CT}(\mathrm{HL})$ is the CT value of the target gene in a HL-treated sample, CT(LL) is the CT value of the same target gene in a LL-treated sample, and $\mathrm{CT}$ (control) is the CT value of the actin gene. Triplicate biological replicates were performed. The qRT-PCR primers are listed in Additional file 1: Table S1.

\section{Results and discussion}

\section{Photosynthetic parameters and pigment analysis}

The maximum quantum yield of photosystem II ( $\mathrm{Fv} / \mathrm{Fm})$ was reduced consecutively under HL or ML treatment exposed for $10 \mathrm{~h}$ (Fig. 1a) and almost did not change between 10 and $12 \mathrm{~h} \mathrm{ML}$ or HL treatment. This trend has been observed in P. tricornutum [25] and in T.

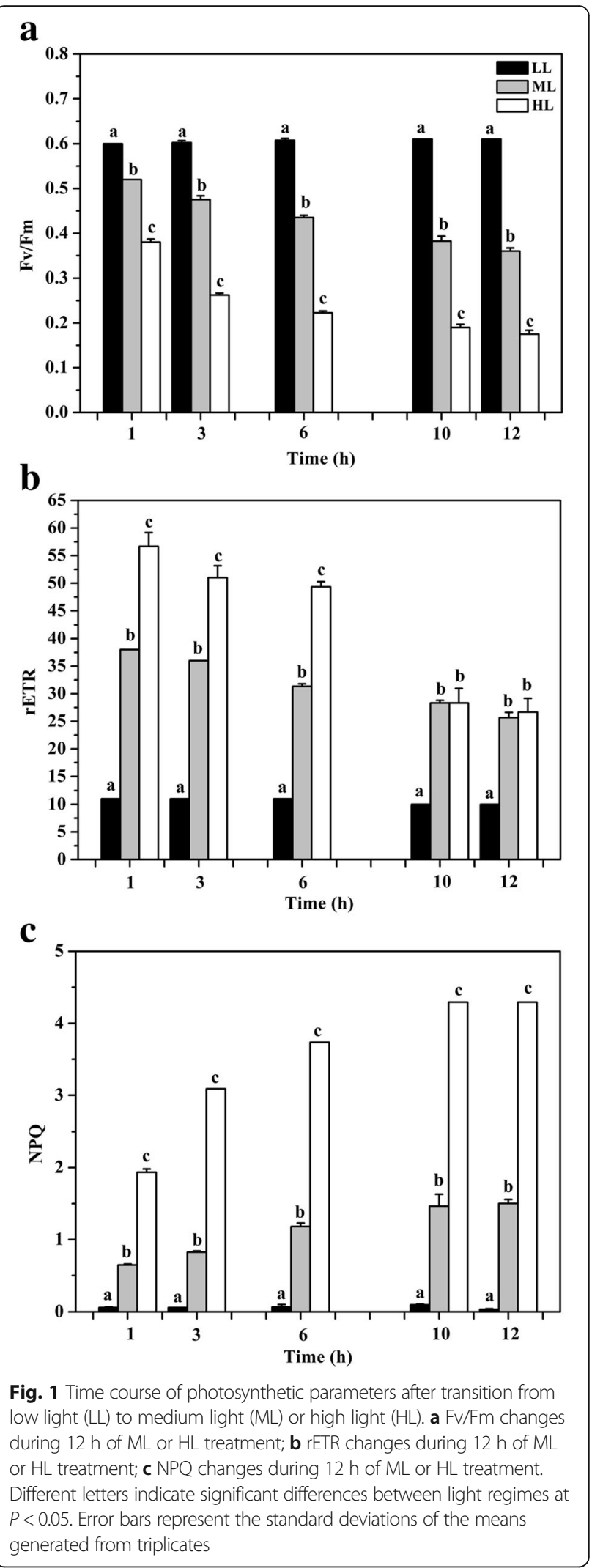

b

c

Fig. 1 Time course of photosynthetic parameters after transition from low light (LL) to medium light (ML) or high light (HL). a Fv/Fm changes during $12 \mathrm{~h}$ of ML or HL treatment; $\mathbf{b}$ rETR changes during $12 \mathrm{~h}$ of $\mathrm{ML}$ Different letters indicate significant differences between light regimes a $P<0.05$. Error bars represent the standard deviations of the means generated from triplicates 
pseudonana [12]. rETR increased rapidly with increasing light intensities and maintained stable during $1 \mathrm{~h}$ of HL or ML treatment, thereafter decreased sharply when cultures were transferred to LL conditions (Fig. 2a). When LL-treated cells were exposed to longer ML or HL stress, a gradual and continuous decrease was observed in rETR over the $10 \mathrm{~h}$ time course (Fig. 1b). These data suggest that photosystem II and electron transport chain in cells are damaged to some extent during longterm HL stress.

NPQ is an important photoprotective mechanism that safely dissipates excess energy as heat. In our study, NPQ increased consecutively during $1 \mathrm{~h}$ of ML or HL treatment, decreased sharply during $1 \mathrm{~h}$ of LL recovery and increased once again during subsequently $1 \mathrm{~h}$ of ML or HL treatment (Fig. 2b). With longer exposure to ML or HL, the level of NPQ was increased continuously during $10 \mathrm{~h}$, but almost remained stable after $10 \mathrm{~h} \mathrm{ML}$ or

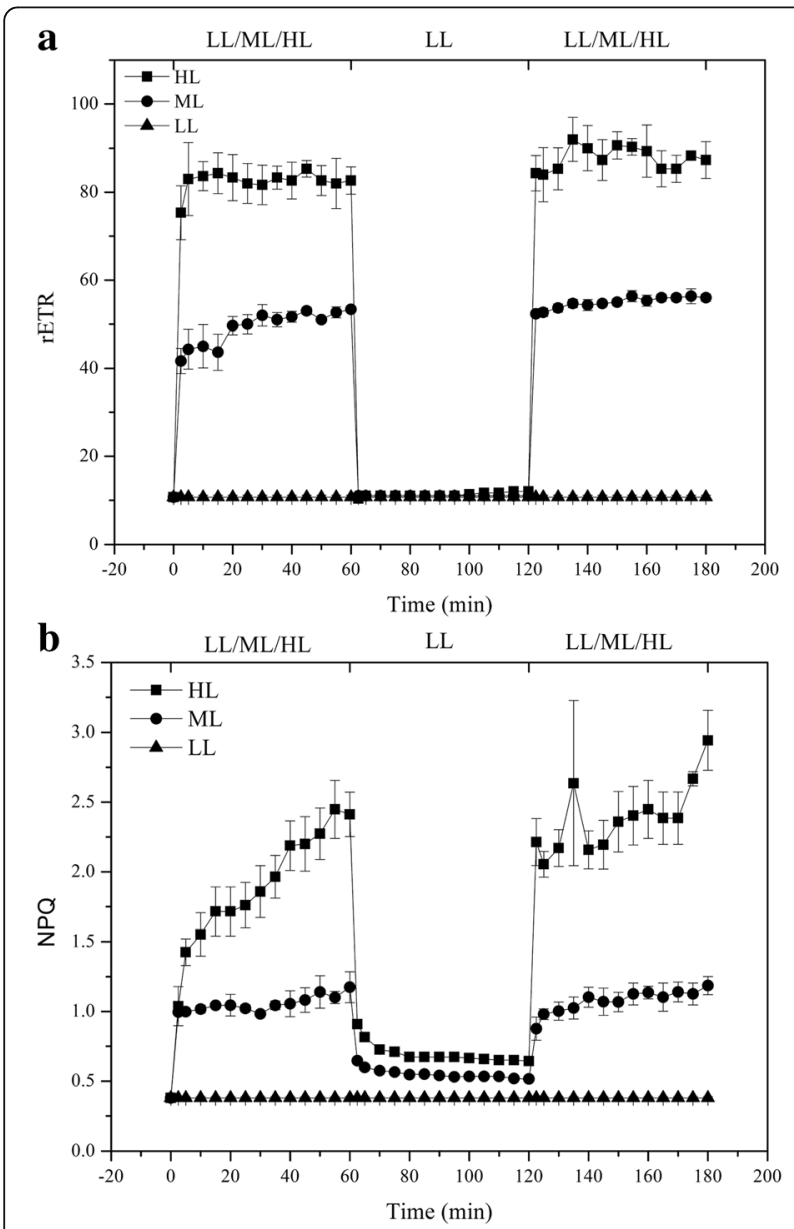

Fig. 2 a rETR changes during $1 \mathrm{~h}$ of $\mathrm{ML}$ or $\mathrm{HL}$ treatment, $1 \mathrm{~h}$ of $\mathrm{LL}$ recovery, and subsequently $1 \mathrm{~h}$ of ML or HL treatment; $\mathbf{b} \mathrm{NPQ}$ changes during $1 \mathrm{~h}$ of $\mathrm{ML}$ or $\mathrm{HL}$ treatment, $1 \mathrm{~h}$ of LL recovery, and subsequently $1 \mathrm{~h}$ of $\mathrm{ML}$ or $\mathrm{HL}$ treatment. Different letters indicate significant differences between light regimes at $P<0.05$. Error bars represent the standard deviations of the means generated from triplicates
HL (Fig. 1c). In addition, NPQ was much higher under HL treatment than under ML treatment. These findings indicate that both the ML and HL can induce photoprotective responses in $T$. pseudonana. The increase of NPQ in T. pseudonana under HL treatment has been reported previously [12]. But, there were the difference in the highest NPQ value in these two studies. This may be due to the growth characteristics of cells, culture conditions, light intensity and instrument difference.

HPLC analyses showed that chlorophyll $a(\mathrm{Chl} a)$, fucoxanthin, Ddx and Dtx were the dominant pigments in this alga (Fig. 3). Compared to LL, Chl $a$ and fucoxanthin content did not change considerably during $12 \mathrm{~h}$ of ML or HL stress (Fig. 3a and b). In contrast, there was a gradual and continuous increase in Dtx concentration (Fig. 3c). Meanwhile, the Dtx content per cell increased with increasing light intensities, and the Dtx content in cultures under HL treatment was 2 to 3 times that of Dtx in cultures under ML treatment over the culture period (Fig. 3c). The results indicate that Dtx accumulation plays a vital role in photoprotection of diatoms. It has been shown that increased Dtx is vital for maintaining high level of NPQ during prolonged HL treatment [12].

As far as Ddx was concerned, its content showed a drastic change under ML or HL stress. Under ML stress, Ddx content in the culture increased markedly in the first $6 \mathrm{~h}$, whereas it fluctuated under HL stress over the whole course of the experiment (Fig. 3d). Compared to $\mathrm{LL}$, the Ddx content was upregulated significantly in cultures exposed to ML for 3,6 , and $12 \mathrm{~h}$, but it was just elevated in cultures exposed to HL for $3 \mathrm{~h}$ (Fig. 3d). These data indicate that excess light treatment elicits de novo synthesis of the Dtx $+\mathrm{Ddx}$ pool. It is likely that increased Dtx + Ddx pool consume partial excess light energy. It has also been shown that the de novo synthesis of Dtx + Ddx could enhance the antioxidant activity within the thylakoid membranes during prolonged high-light stress [14]. In a previous study on T. pseudonana, Dtx content per cell gradually increased while there was slight change in Ddx content during $9 \mathrm{~h}$ of HL treatment [12]. Our results support the conclusion that the accumulation of Dtx is not from the conversion of $\mathrm{Ddx}$ during long-term $\mathrm{HL}$ stress [12].

Changes of fatty acid composition and neutral lipid content It has been shown that excess light energy might increase neutral lipid content in marine diatom Skeletonema marinoi [26], which further affect the growth of zooplankton in the marine food chain. Here, we analyzed fatty acid composition and neutral lipid content in T. pseudonana under HL stress. After $10 \mathrm{~h}$ of HL stress, saturated fatty acid content increased significantly (Fig. 4b), whereas monounsaturated and polyunsaturated fatty acid contents decreased significantly. As shown in Fig. 4a, the dominant 

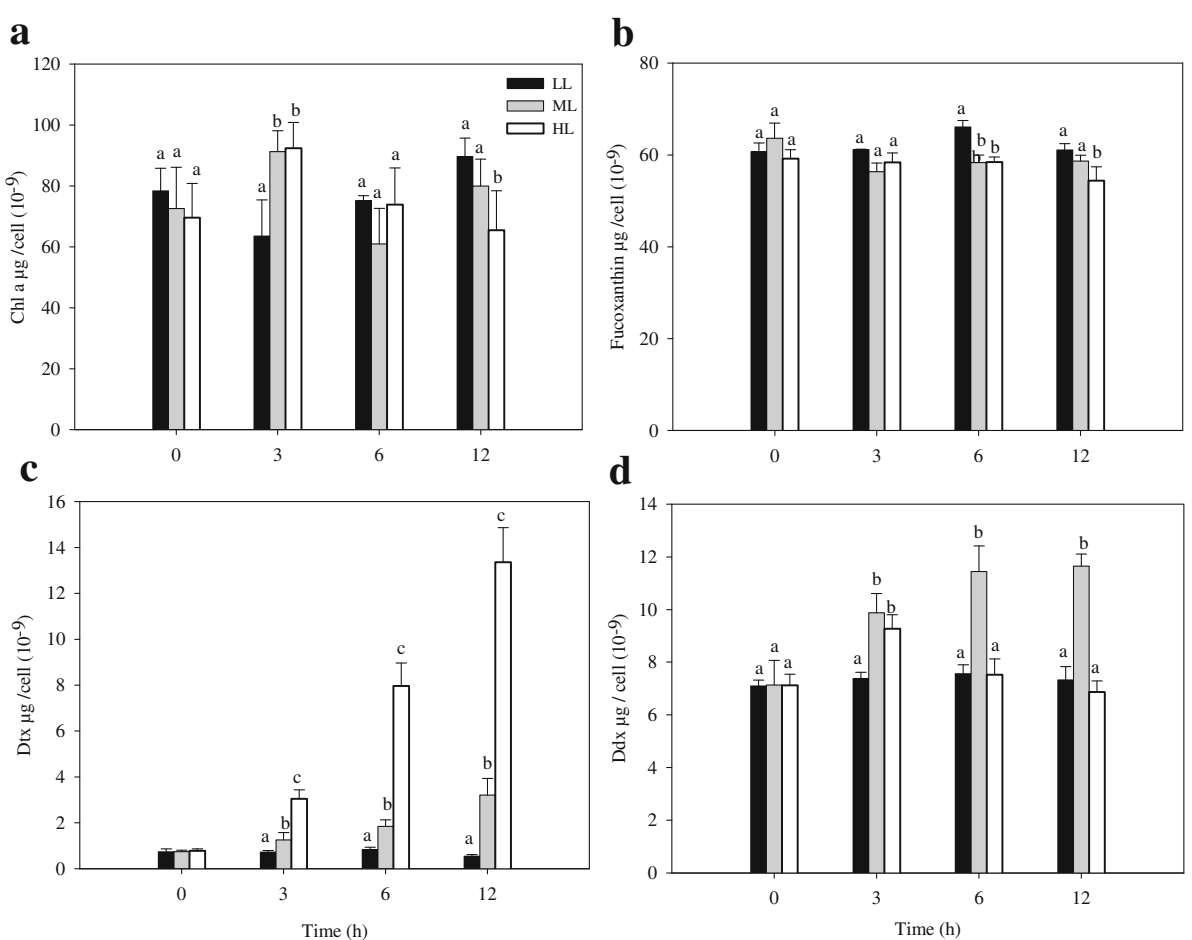

Fig. 3 The Chl $a(\mathbf{a})$, fucoxanthin (b), Dtx (c) and Ddx (d) contents per cell as a function of medium light (ML) or high light (HL) exposure time. Cultures were grown exponentially at a light intensity of $30 \mu \mathrm{mol}$ photons $\mathrm{m}^{-2} \mathrm{~s}^{-1}$ for 4 weeks prior to $\mathrm{HL}$ treatment. Error bars represent the standard deviations of the means from three biological replicates. Different letters indicate significant differences between light regimes at $P<0.05$

fatty acids present in the fatty acid profile were C14:0, $\mathrm{C} 16: 3 \omega 3, \mathrm{C} 16: 1 \triangle 11, \mathrm{C} 16: 0, \mathrm{C} 18: 1 \Delta 9, \mathrm{C} 20: 5 \omega 3$, and $\mathrm{C} 22: 6 \omega 3$ (number of carbons: number of double bonds, where positions of double bonds are indicated with $\Delta$ [counting from the carboxyl group] or $\omega$ [counting from the methyl group]). Among the alterations in fatty acid composition (\%) within the total fatty acids, it was observed that levels of C14:0 and C16:0 were markedly increased under HL, while no significant change in $\mathrm{C} 18: 0$ and $\mathrm{C} 24: 0$ was observed. In addition, $\mathrm{C} 18: 1 \triangle 9, \mathrm{C} 20: 5 \omega 3$ and $\mathrm{C} 22: 6 \omega 3$ were significantly decreased after HL stress. The level of $\mathrm{C} 20: 5 \omega 3$ was reduced by approximately $70 \%$, and C22:6 $\omega 3$ was below the detection limit. The level of $\mathrm{C} 16: 3 \omega 3$ was found to increase after HL stress. Interestingly, C16:1 $\triangle 11$ increased slightly after HL stress. These data indicated that HL stress altered the fatty acid composition. This alteration may raise the capability to resist excess light stress. Similar to N depletion [27], increased saturated fatty acid synthesis may alleviate reactive oxygen species formation at PSII by sequestering excess electrons moving through the photosynthetic electron transport chain.

Surprisingly, the neutral lipid content (triacylglycerol, TAG) determined by Nile red fluorescence staining showed that neutral lipid increased significantly after HL treatment (Fig. 5a). In addition, a significant increase was observed in size and number of lipid droplets in a typical diatom cell (Fig. 5b). These data suggest that HL stress elicits TAG accumulation in diatom cells. In microalgae, TAG accumulation under environmental stress conditions may be associated with plastid membrane turnover or degradation [28]. Thus, it is hypothesized that the membrane glycerolipids with polyunsaturated fatty acids may be degraded to produce additional TAG during HL treatment.

\section{Proteomic responses to $\mathrm{HL}$ treatment}

Based on the data above, it has been shown that HL stress lead to significant changes in diatom physiology. Considering that diatoms are frequently subjected to varying light irradiance in surface waters of ocean, HL were used as irradiance condition to examine the effect of excess light on the proteome of T. pseudonana. Transcriptional studies indicate that the acclimation mechanisms in diatoms can be divided into an initial response phase $(0-0.5 \mathrm{~h})$, an intermediate acclimation phase $(3-12 \mathrm{~h})$ and a late acclimation phase (12-48 h) [25]. A strong and rapid regulation of genes encoding proteins involved in photosynthesis, pigment metabolism, reactive oxygen species (ROS) scavenging systems, Dtx/Ddx cycle, and carbon metabolism is observed during $12 \mathrm{~h}$ of HL treatment. It is inferred that proteomic responses should be later than transcriptional changes, thus $10 \mathrm{~h}$ of $\mathrm{HL}$ 


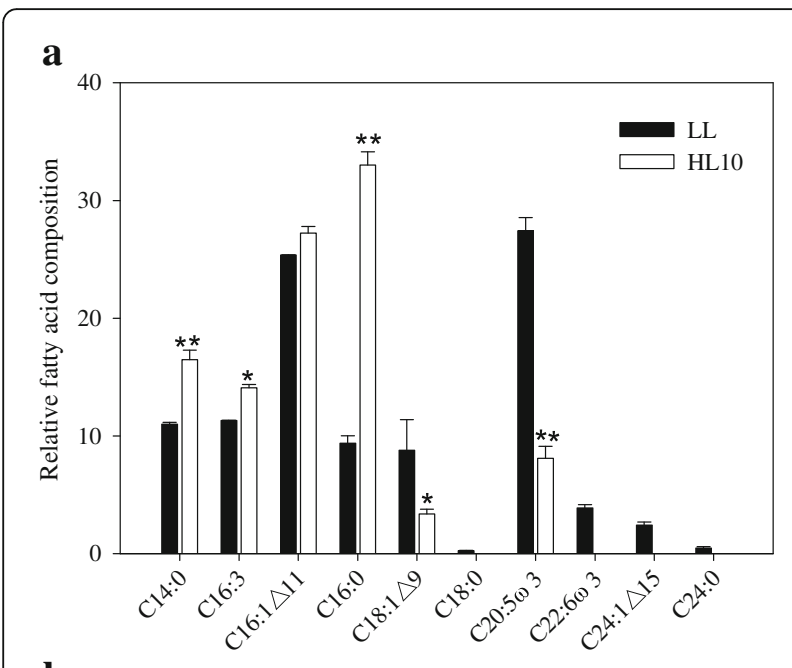

b

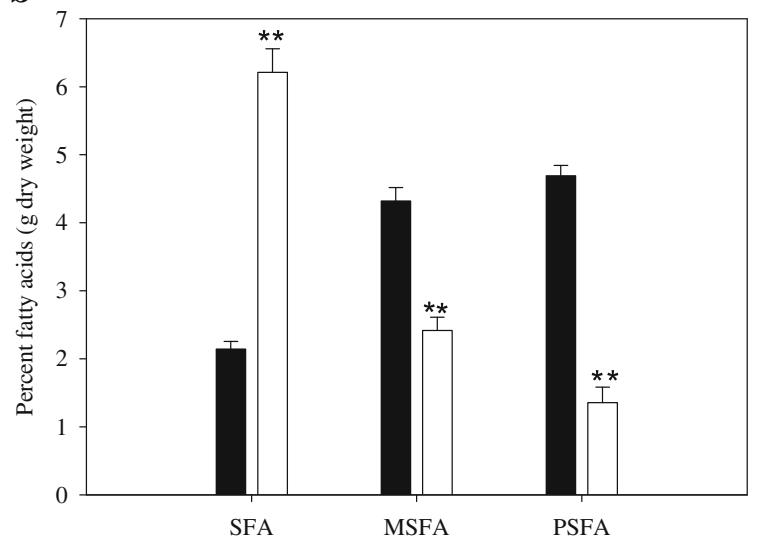

Fig. 4 Changes in fatty acid composition in T. pseudonana after $10 \mathrm{~h}$ of high light $(\mathrm{HL})$ treatment. a Relative fatty acid composition (percentage of total fatty acids); $\mathbf{b}$ total fatty acids (TFA), saturated fatty acids (SFA), monounsaturated fatty acids (MSFA) and polyunsaturated fatty acids (PSFA). Low light (LL)-acclimated cells were shifted into $\mathrm{HL}$ and sampled at $10 \mathrm{~h} .{ }^{*}$ indicates significant differences $(P<0.05)$ relative to LL-acclimated cells

treatment was chosen to track short-term photoprotective mechanisms of diatoms. The duration may reflect the changes after diatom cells are subjected to a daytime irradiance in the oceanic surface waters.

\section{Protein identification, quantification and $q R T-P C R$ verification}

Protein samples from LL-acclimated and HL-treated cultures were labeled by six different iTRAQ tags $(113,115$, $121,114,116$, and 118). Each treatment consisted of three biological replicates. Detailed interpretation procedure of protein labeling and identification are described in Additional file 2: Figure S1. After data search by Mascot, a total of 4143 proteins were identified with one or more unique peptides (Additional file 3: Table S2). Among them, approximately $66 \%$ of total proteins were matched by two or more unique peptides. The identified proteins

\section{a}

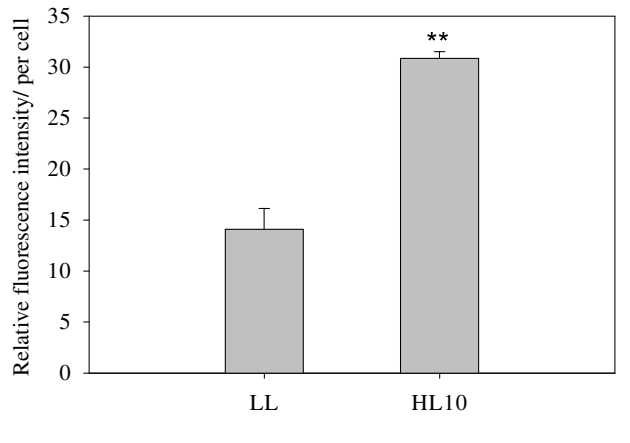

b

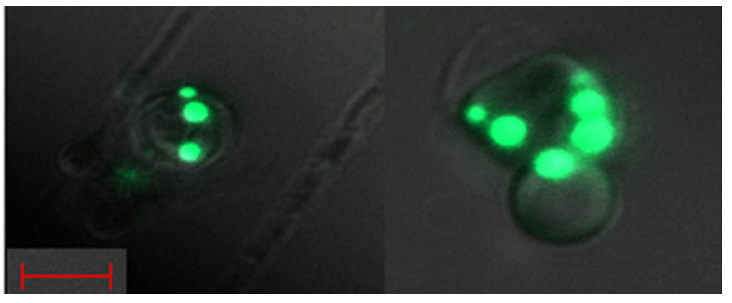

LL

HL10

Fig. 5 Accumulation of TAGs during $10 \mathrm{~h}$ of high light (HL) stress. a TAG content determined by Nile red staining; $\mathbf{b}$ confocal microscopy images of Nile red-stained cells subjected to $\mathrm{HL}$ treatment. * indicates significant differences $(P<0.05)$ relative to low light $(L L)$-acclimated cells. The scale bar indicates $5 \mu \mathrm{m}$

were annotated by blasting against UniProt/Swiss-Prot, Gene Ontology (GO) and Cluster of Orthologous Groups (COG) databases. As a result, about $65 \%$ of proteins could be assigned to a detailed function. Protein quantification was performed for these proteins matched by two or more unique peptides.

For protein quantification, repeatability among three biological replicates was analyzed (Additional file 4: Figure S2). Error distribution showed that median error was from 0.085 to 0.12 for the three biological replicates, and approximately 75 to $78 \%$ of proteins varied within $20 \%$ of median value, which is a reasonable range for shotgun proteomics. Based on the error distribution among replicates, we chose $>1.5$ - or $<0.67$-fold change as the threshold of differentially expressed proteins. Following the criteria, 132 and 11 were upregulated and downregulated, respectively, under HL stress (Additional file 5: Table S3). These proteins were classified based on GO function (Table 1). Proteins that were involved in protein synthesis/degradation, photosystem and electron transport chain, and photoreceptor and signal were predominant in GO categories.

The transcript abundance of genes encoding eight upregulated proteins was determined by qRT-PCR (Fig. 6). Among these genes, expression levels of five genes including Lhcx4, antibiotic biosynthesis monooxygenase (AMOS), peroxiredoxin $\mathrm{Q}$, fatty acid desaturase (FADS), 
Table 1 Number and percentage of the differentially expressed proteins (DEP) grouped by Gene Ontology

\begin{tabular}{lll}
\hline GO group & $\begin{array}{l}\text { Number of DEP in } \\
\text { HL compared to LL }\end{array}$ & \% of total DEP \\
\hline Carbon fixation & 2 & 1.4 \\
Xanthophyll cycle & 1 & 0.7 \\
Photosystem and electron & 12 & 8.4 \\
transport chain & \\
Photoreceptor and signal & 12 & 8.4 \\
Carbon metabolism & 4 & 2.8 \\
Protein synthesis/degradation & 35 & 24.5 \\
Fatty acid, steroid and & 7 & 4.9 \\
terpenoid synthesis & & \\
Oxidative stress & 8 & 5.6 \\
Cell cycle and cell division & 2 & 1.4 \\
DNA/RNA replication, & 4 & 2.8 \\
modification and repair & & 1.4 \\
Energy production & 2 & 1.4 \\
Nitrogen metabolism & 2 & 4.2 \\
Transport & 6 & 0.7 \\
CO2 concentration & 1 & 2.8 \\
Cell wall and extracellular & 4 & 9.8 \\
enzyme & & 18.9 \\
No GO & 14 & \\
Function unknown & 27 & \\
\hline
\end{tabular}

and Lhcx6 were markedly upregulated after cells were exposed to HL for $3 \mathrm{~h}$, but were almost back to LL levels after $10 \mathrm{~h} \mathrm{HL}$ (Fig. 6b, c, d, e and f). The data demonstrated that the five genes could be induced by shortterm HL stress and supported indirectly proteomic results. For other three genes, glycolate oxidase, chitinase, long-chain-fatty-acid-CoA ligase (LCFAL), no significant difference was observed in their transcript abundance after cells were exposed to HL for 3 and $10 \mathrm{~h}$ (Fig. 6a, g and $\mathrm{h}$ ). It is assumed that they might be regulated at posttranscriptional or translational or post-translational level.

\section{Light-harvesting complex (LHC) and XC}

Diatoms possess a large number of members of LHC superfamily, the fucoxanthin $\mathrm{Chl} a / c$ proteins (FCPs). These FCPs fall into three groups: the major fucoxanthin $\mathrm{Chl} a / c$ proteins (Lhcf), the red algal-like proteins (Lhcr) and the LI818-like proteins (Lhcx). Interestingly, in PSI and PSII, only FCPs were differentially regulated by HL. After $10 \mathrm{~h}$ of $\mathrm{HL}$ treatment, expression of $4 \mathrm{FCPs}$, Lhcx4, Lhcx6, Lhcr5 and Lhcr8, were increased by 2.1to 6.3-fold and no FCPs decreased (Table 2). The results suggest that Lhcx4, Lhcx6, Lhcr5 and Lhcr8 are involved in photoprotection in T. pseudonana during HL stress. These FCPs may bind to Dtx and play a role in photoprotection. The Lhcx6 protein from T. pseudonana has been shown to participate in heat dissipation of excess light energy during HL stress [12]. Interestingly, a violaxanthin de-epoxidase-like (VDL) increased by 1.64-fold after $10 \mathrm{~h}$ of HL treatment (Table 2). It is deduced that the VDL is involved in the conversion of Ddx to Dtx under HL.

\section{Carbon metabolism}

We identified two ribulose-1,5 bisphosphate carboxylase/ oxygenases (Rubisco) involved in the Calvin-Benson cycle in the proteome of T. pseudonana. Among them, a Rubisco increased by 1.83-fold in cells during $10 \mathrm{~h}$ of $\mathrm{HL}$ treatment (Table 2), whereas another Rubisco did not change. In addition, a phosphoribulokinase (PKK) that is involved in the Calvin-Benson cycle increased by 1.95-fold in HL-treated cells (Table 2). It is inferred that the Calvin cycle may be elevated in HL-treated cells relative to LL-acclimated cells.

Out of two gamma carbonic anhydrases (CA) identified, one increased by 2.88 -fold after $10 \mathrm{~h}$ of HL treatment (Table 2). In addition, two of phosphoenolpyruvate carboxylases (PEPCase), one phosphoenolpyruvate carboxykinase (PEPCK), one pyruvate phosphate dikinase (PPDK) which are required for $\mathrm{CO}_{2}$-concentrating mechanisms (CCM) of C4-metabolism were identified in our study and they were not affected after HL treatment. The genes encoding PEPCase, PEPCK and PPDK have been identified in T. pseudonana genome [29]. Our data confirm the presence of CCM in T. pseudonana. It has been shown that high light irradiance increased CA activity, thus recycled $\mathrm{CO}_{2}$ leaking out of the chloroplast more effectively [30]. Thus, the CA upregulation suggested elevated CCM in HL-treated cells. The elevated CCM in C4-metabolism might increase consumption for cellular energy [30, 31].

It is noted that a phosphoglycerate kinase (PGK) increased by 1.67 -fold in cells experiencing $10 \mathrm{~h}$ of HL treatment (Table 2). The PGK were predicted to be localized in the cytoplasm and this clue suggests that the glycolysis pathway in cytoplasm may be accelerated after HL treatment. A glycolate oxidase (GOX) that is a key enzyme of the photorespiration/glyoxylate cycle, increased by 2.3fold after $10 \mathrm{~h}$ of $\mathrm{HL}$ treatment (Table 2). In higher plants, photorespiration can reduce the damage caused by the oxygenation reaction of Rubisco. When $\mathrm{O}_{2}$ reacts to ribulose-1,5-bisphosphate, one molecule of 2-P-glycolate and one molecule of 3-P-glycerate are produced. The former is degraded via the photorespiratory pathway, which avoids its inhibition for the Calvin cycle enzyme, triosephosphate isomerase. It is likely that photorespiration activity increased after short-term HL treatment. It suggested that diatoms may alleviate HL stress by releasing more fixed carbon [32]. 


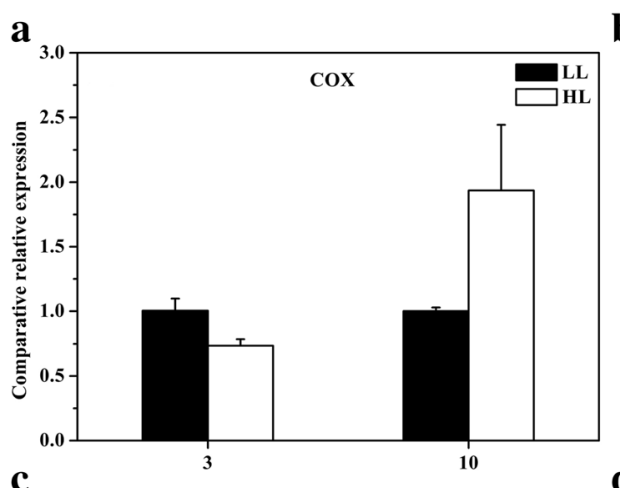

b
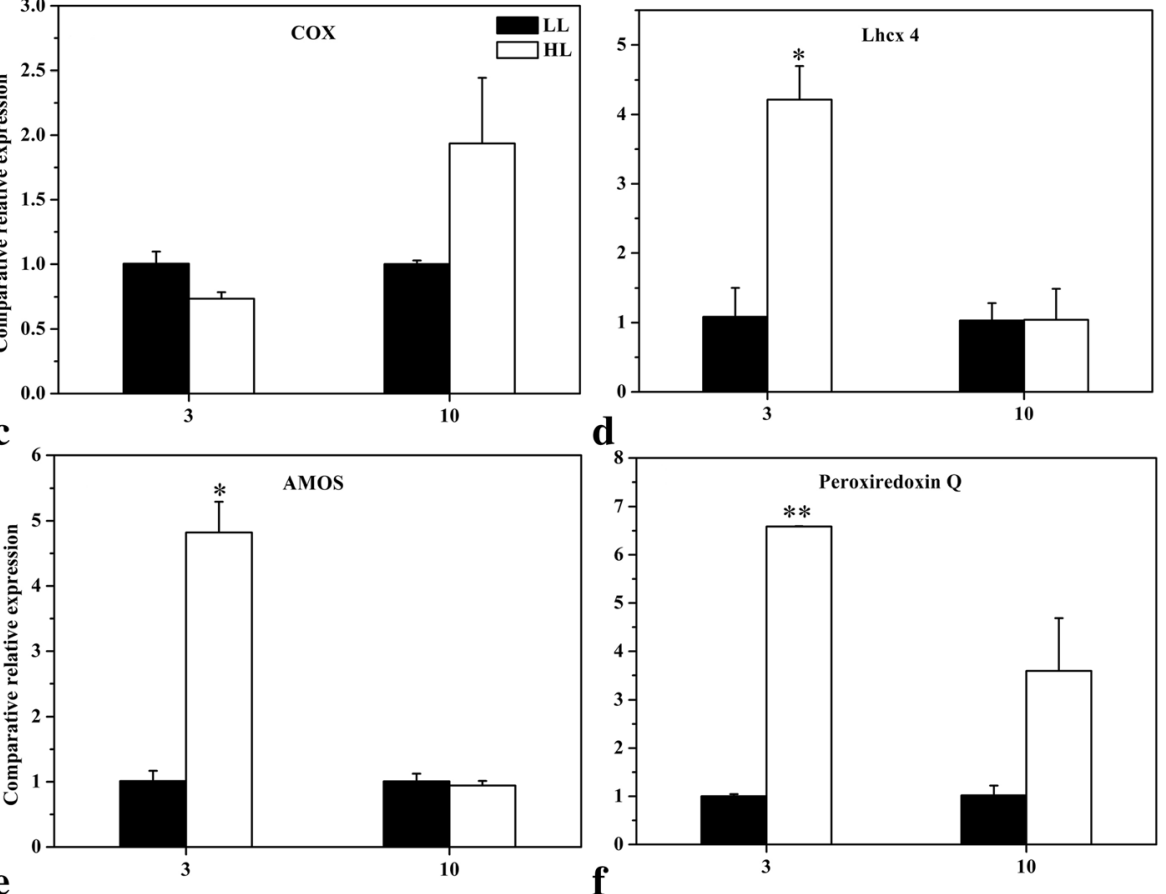

d
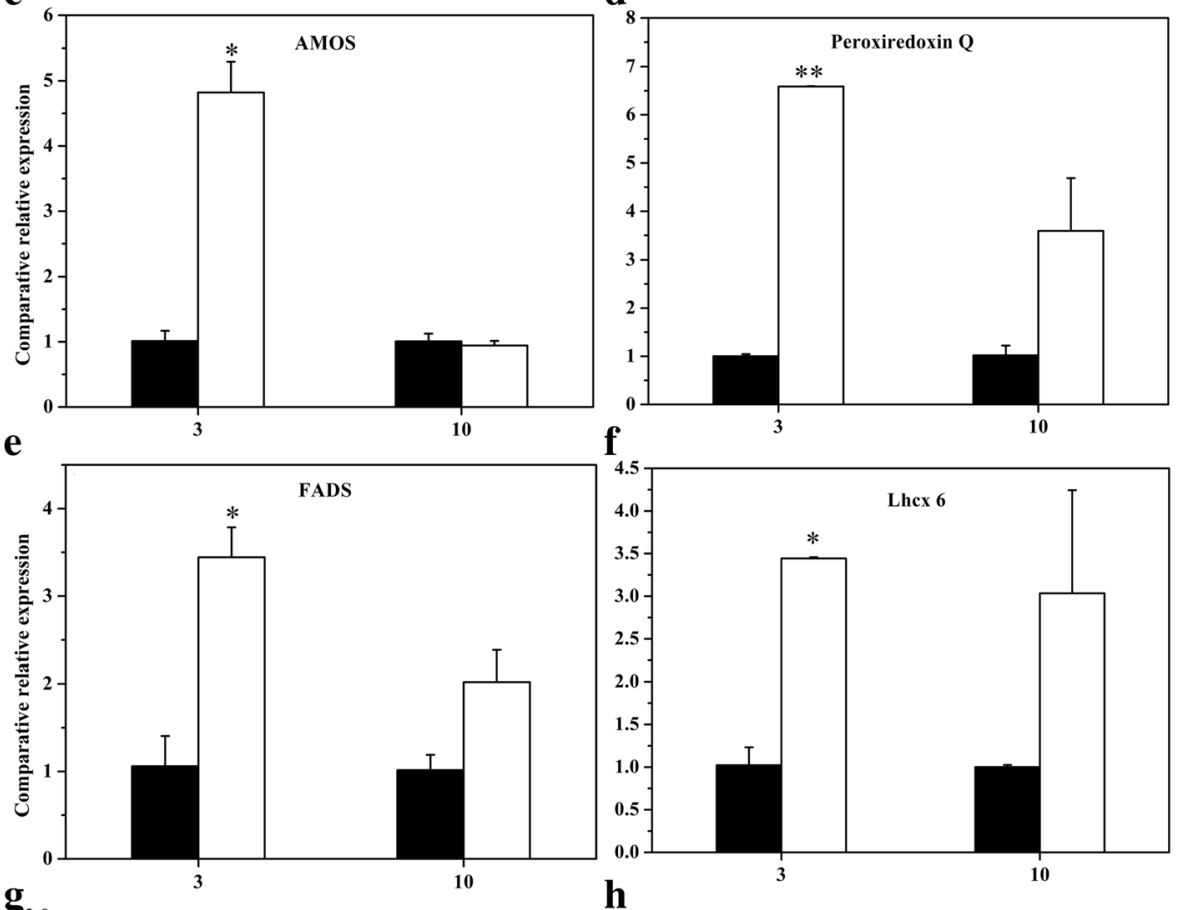

f

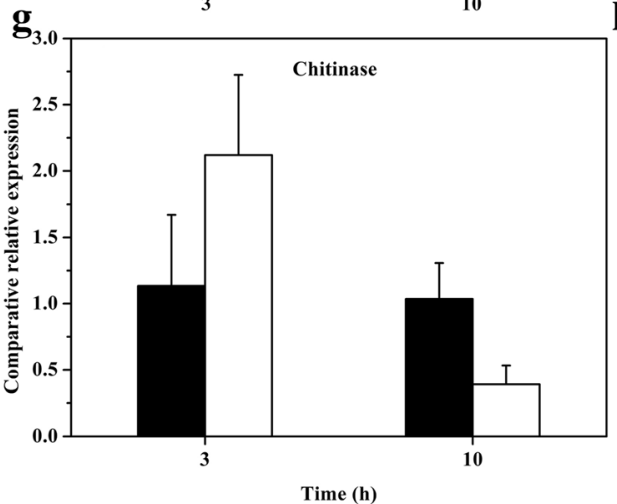

h
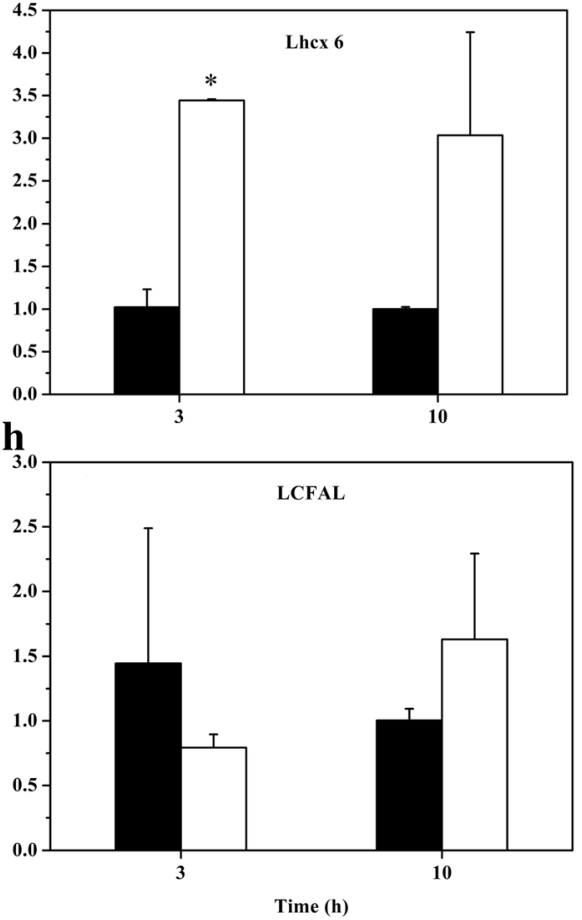

Fig. 6 Comparative relative expression ( $\triangle \triangle C T$ ) patterns of genes a COX, b Lhcx 4, c AMOS, d peroxiredoxin Q, e FADS, f $L$ hcx 6, $\mathbf{g}$ chitinase, $\mathbf{h} L C F A L$ encoding eight differentially expressed proteins identified in the proteomic study when low light (LL)-acclimated cells were exposed to high light (HL) for 3 and $10 \mathrm{~h}$. Error bars represent the standard deviations of the means generated from triplicates. *indicates significant differences $(P<0.05)$ relative to LLacclimated cultures. The abbreviations are as follows: glycolate oxidase, GOX; antibiotic biosynthesis monooxygenase, AMOS; fatty acid desaturase, FADS; long-chain-fatty-acid-CoA ligase, LCFAL 
Table 2 The differentially expressed proteins identified in T. pseudonana under $10 \mathrm{~h}$ of HL which are involved in important metabolic pathways disscussed in this study

\begin{tabular}{|c|c|c|c|}
\hline Name & Accession number & Number of unique peptides & Fold change (HL/LL) \\
\hline \multicolumn{4}{|l|}{ Light-harvesting complex proteins and xanthophyll cycle } \\
\hline Fucoxanthin chl a/c light-harvesting protein (Lhcr8) & gi|220969130 & 4 & 2.04 \\
\hline Fucoxanthin chlorophyll a/c light-harvesting protein (Lhcr5) & gi|209583680 & 6 & 3.64 \\
\hline Fucoxanthin chlorophyll a/c protein, LI818 clade (Lhcx6) & gi|220969145 & 5 & 3.84 \\
\hline Fucoxanthin chl a/c light-harvesting protein (Lhcr8) & gi|220968241 & 4 & 2.32 \\
\hline Fucoxanthin chlorophyll a/c protein, LI818 clade (Lhcx4) & gi|220974177 & 2 & 6.34 \\
\hline Violaxanthin de-epoxidase-like 1 & gi|220974348 & 3 & 1.64 \\
\hline \multicolumn{4}{|l|}{ Carbon metabolism } \\
\hline Ribulose-1,5-bisphosphate carboxylase/oxygenase large subunit & gi|4093213 & 2 & 1.83 \\
\hline Phosphoribulokinase & gi|220970595 & 4 & 1.95 \\
\hline Carbonic anhydrase & gi|589908190 & 3 & 2.88 \\
\hline Phosphoglycerate kinase & gi|220968544 & 10 & 1.67 \\
\hline Glycolate oxidase & gi|220975250 & 4 & 2.26 \\
\hline Chitinase & gi|220967856 & 8 & 1.62 \\
\hline Peptidoglycan-associated outer membrane protein & gi|220969879 & 2 & 1.75 \\
\hline Antibiotic biosynthesis monooxygenase & gi|220968047 & 2 & 5.14 \\
\hline \multicolumn{4}{|l|}{ Lipid metabolism } \\
\hline Long-chain-fatty-acid-CoA ligase & gi|209585777 & 3 & 1.61 \\
\hline Fatty acid desaturase & gi|220973009 & 6 & 2.21 \\
\hline Cyclopropane-fatty-acyl-phospholipid synthase & gi|220969789 & 4 & 1.98 \\
\hline Serine palmitoyltransferase & gi|220968852| & 4 & 1.68 \\
\hline Omega-6 fatty acid desaturase & gi|220975284 & 3 & 2.14 \\
\hline Nucleoside-diphosphate-sugar epimerase & gi|220967789 & 11 & 1.59 \\
\hline \multicolumn{4}{|l|}{ Signaling proteins and transcription factors } \\
\hline Retinol dehydrogenase & gi|220978263 & 7 & 1.68 \\
\hline Retinol dehydrogenase & gi|220973743 & 4 & 4.39 \\
\hline Death-specific protein 1 & gi|156600453 & 2 & 2.26 \\
\hline Nucleoprotein TPR & gi|220969246 & 16 & 1.63 \\
\hline EH domain-containing protein & gi|220977976 & 7 & 2.69 \\
\hline ATP-dependent RNA helicase ded-1 & gi|220972152 & 7 & 2.46 \\
\hline Uncharacterized aarF domain-containing protein kinase At4g31390 & gi|220969732 & 7 & 1.61 \\
\hline Ran-type small G protein & gi|220976883 & 4 & 1.50 \\
\hline EF-Hand 1, calcium-binding site & gi|220976291 & 3 & 2.01 \\
\hline U6 snRNA-associated Sm-like protein LSm7 & gi|220969887 & 2 & 2.07 \\
\hline \multicolumn{4}{|l|}{ Oxidative stress } \\
\hline Peroxiredoxin Q, chloroplastic & gi|220975768 & 2 & 7.83 \\
\hline Peptide methionine sulfoxide reductase MsrA & gi|220976092 & 5 & 2.2 \\
\hline Thiol-disulfide isomerase & gi|220969193 & 11 & 1.84 \\
\hline Co-chaperonin GroES (HSP10) & gi|220971585 & 4 & 2.13 \\
\hline Heat shock protein DnaJ & gi|220977601 & 12 & 1.76 \\
\hline Chaperone protein dnaJ & gi|220971047 & 7 & 1.77 \\
\hline high light induced protein 2 & gi|220977122 & 2 & 1.57 \\
\hline Stress-inducible protein sti1 & gi|220969212 & 6 & 1.78 \\
\hline
\end{tabular}


Several enzymes that are involved in synthesis and degradation of chitin were identified in T. pseudonana, including chitin synthetase, chitin deacetylase, and chitinase. Cell wall chitin content in diatoms was found to affect sinking of diatoms in the surface layers of the ocean [33]. Diatom sinking is proposed to be a survival strategy for cells in harsh environments and enables them to stay in favorable conditions [34]. In this study, our data confirmed the presence of chitin in diatoms and found that a chitinase was increased by 1.6 -fold following 10 of HL treatment, whereas there was no change in chitin synthetase level (Table 2). This result implies that short-term HL may elicit a decrease in cell wall chitin in diatom. We also identified a peptidoglycan-associated outer membrane protein (PPOM) and an AMOS which were increased by 1.75- and 5.14-fold, respectively, after $10 \mathrm{~h}$ of HL treatment (Table 2). They were predicted to be localized in cell wall and involved in synthesis of polysaccharides. The data suggest that the synthesis of polysaccharides in diatom cell walls may be elevated after HL treatment. The hydrophilic nature of polysaccharides probably fortifies the stability and rigidity of cell walls [35], which helps the diatoms to resist HL stress.

\section{Lipid metabolism}

We identified five enzymes involved in the synthesis of fatty acids or lipids that increased by 1.61- to 2.21 -fold after $10 \mathrm{~h}$ of HL treatment, including LCFAL, FADS, cyclopropanefatty-acyl-phospholipid synthase (CFAPS), serine palmitoyltransferase (SRPS) (Table 2). In higher plants, the synthesized fatty acid in the plastid is converted to acyl-CoA by long-chain fatty acid CoA ligase (LCFAL) [36], which is subsequently used for synthesis of TAG and phospholipids. CFAPS is involved in synthesis of phospholipid. In addition, a nucleoside-diphosphate-sugar epimerase (NDSE) that is involved in UDP-galactose supply for galactolipid biosynthesis of thylakoid membranes in rice chloroplasts [37] was found to be upregulated by 1.59 -fold after $10 \mathrm{~h}$ of HL treatment (Table 2). Overexpression of NDSE gene in rice was reported to increase photosynthetic efficiency, biomass, and grain production [37]. It is assumed that upregulation of LCFAL, CFAPS, and NDSE may increase TAG in cells, phospholipids, and galactolipids in thylakoid membranes, which may elevate utilization efficiency of light energy and strengthen membrane stability under HL stress. Increased TAG has been observed in the physiological studies mentioned above. The SRPS is a key enzyme in the biosynthesis of sphingolipids [38] and its upregulation suggests that cellular sphingolipids content may be increased after HL stress. Plant sphingolipids have been shown to be involved in signal transduction, membrane stability, and stress responses [38]. Interestingly, two of FADSs increased by 2.14to 2.21 -fold after HL treatment. FADSs catalyze key reactions in the synthesis of polyunsaturated fatty acids. It is likely that FADSs may be responsible for the increased percentage of $C 16: 3 \omega 3$ and $C 16: 1 \triangle 11$ within total fatty acids.

Photoreceptors, signaling proteins, and transcription factors We identified three aureochromes, which have been regarded as photoreceptors in $P$. tricornutum and $T$. pseudonana [39]. Under HL stress, no significant change was observed in relative abundance of aureochromes, suggesting that light signal transmission might be not regulated by change of expression abundance of aureochromes. In addition, five putative retinol dehydrogenases (RDS) were identified in T. pseudonana and two were shown to be upregulated by 1.68 - and 4.39 -fold, respectively, after $10 \mathrm{~h}$ of HL treatment (Table 2). RDS is responsible for the conversion of retinol to retinal in the visual cycle, which is the chromophore of the photoreceptor rhodopsin. Identification and changes in RDS suggest the likely presence of homologous proteins with rhodopsin in diatoms. In addition, upregulation of RDSs under HL treatment suggests that they may be involved in transmission of light signal in cells.

Eight signaling proteins or transcription factors were found to be differentially expressed after HL treatment (Table 2), including ran-type small G protein, DSP1, U6 snRNA-associated Sm-like protein LSm7, nucleoprotein TPR, EH domain-containing protein, and ATP-dependent RNA helicase ded-1. These proteins may allow light signals from photoreceptors to trigger nuclear gene expression that facilitate various cellular processes. Interestingly, the DSP1 has been identified in T. pseudonana in a previous study, which showed that DSP1 localizes to the plastid and that clone lines overexpressing DSP1 had increased CEF around photosystem I [15]. In this study, upregulation of DSP1 may increase the flux of electrons through CEF, thus reducing electrons produced by excess light.

\section{Nitrogen metabolism}

Interestingly, 21 to 25 ribosomal proteins that make up the ribosomal subunits were upregulated significantly after $10 \mathrm{~h}$ of HL (Table 3 and Additional file 5: Table S3). Three translation initiation factors were shown to be upregulated by 1.6- to 1.9-fold after $10 \mathrm{~h}$ of HL treatment (Table 3). Among them, five ribosomal proteins and an IF-2 were localized to the chloroplasts. Therefore, it is deduced that protein synthesis might be elevated in cytoplasm and chloroplast after HL treatment. This is in agreement with the observation that 132 proteins showed upregulation and 11 downregulation after HL treatment. A Tha4/Hcf106 protein was shown to be upregulated by 3.0-fold after HL treatment (Table 3). This protein is involved in the thylakoid $\Delta \mathrm{pH}$-dependent pathway that transports nuclear-encoded thylakoid proteins into chloroplast stroma [40]. Upregulation of Tha4/Hcf106 suggests 
Table $\mathbf{3}$ The differentially expressed proteins identified as involved in nitrogen assimilation, transport and protein synthesis in T. pseudonana under $10 \mathrm{~h}$ of $\mathrm{HL}$ stress

\begin{tabular}{|c|c|c|c|}
\hline Name & $\begin{array}{l}\text { Accession } \\
\text { number }\end{array}$ & $\begin{array}{l}\text { Number of } \\
\text { unique } \\
\text { peptides }\end{array}$ & $\begin{array}{l}\text { Fold } \\
\text { change }\end{array}$ \\
\hline Glutamine synthetase & gi|220969384 & 11 & 1.53 \\
\hline Ornithine cyclodeaminase & gi|220977545 & 5 & 1.99 \\
\hline Urea transporter & gi|220971788 & 4 & 1.64 \\
\hline $\mathrm{ABC}$ transporter & gi|220977750 & 5 & 2.56 \\
\hline $\mathrm{ABC}$ transporter & gi|220975701 & 26 & 1.65 \\
\hline $\mathrm{ABC}$ transporter & gi|220968000 & 4 & 1.78 \\
\hline Tha4/Hcf106 protein & gi|220977108 & 3 & 2.98 \\
\hline $\begin{array}{l}30 \text { S ribosomal protein S11, } \\
\text { chloroplastic }\end{array}$ & gi|125987672 & 2 & 4.69 \\
\hline $60 S$ ribosomal protein $\mathrm{L} 27 \mathrm{a}$ & gi|220976691 & 4 & 1.69 \\
\hline Translation initiation factor elF-2 & gi|209586387 & 16 & 1.64 \\
\hline $40 S$ ribosomal protein $\$ 18$ & gi|220976243 & 5 & 3.3 \\
\hline 40 S ribosomal protein $\$ 20$ & gi|220974843 & 3 & 2 \\
\hline Translation initiation factor 1 & gi|209585886 & 3 & 1.62 \\
\hline $\begin{array}{l}50 S \text { ribosomal protein } L 5 \text {, } \\
\text { chloroplastic }\end{array}$ & gi|224493190 & 7 & 2.11 \\
\hline 605 ribosomal protein $\mathrm{L} 13$ & gi|220974751 & 4 & 1.56 \\
\hline 40 S ribosomal protein $\$ 25$ & gi|220970481 & 2 & 2.46 \\
\hline $40 S$ ribosomal protein S11 & gi|220973471 & 8 & 2.04 \\
\hline $60 S$ ribosomal protein $L 27$ & gi|220970128 & 7 & 2.26 \\
\hline $\begin{array}{l}30 \text { ribosomal protein } 56 \text {, } \\
\text { chloroplastic }\end{array}$ & gi|220967765 & 8 & 1.93 \\
\hline 605 ribosomal protein L12-1 & gi|220976821 & 4 & 2.57 \\
\hline $60 S$ ribosomal protein $L 35 a$ & gi|220971603 & 4 & 2.16 \\
\hline $60 S$ ribosomal protein $L 24$ & gi|220975456 & 4 & 1.48 \\
\hline $40 S$ ribosomal protein S26-B & gi|220973256 & 2 & 2.45 \\
\hline 605 ribosomal protein $L 6$ & gi|220970841 & 9 & 1.99 \\
\hline 405 ribosomal protein 59 & gi|220974914 & 5 & 1.62 \\
\hline $60 S$ ribosomal protein L23a & gi|220973318 & 6 & 2.65 \\
\hline 605 ribosomal protein $L 23$ & gi|220971079 & 6 & 1.72 \\
\hline 605 ribosomal protein L19 & gi|220976636 & 2 & 2.39 \\
\hline 605 ribosomal protein L11 & gi|220974977 & 5 & 2.03 \\
\hline Translation initiation factor IF-2 & gi|220974959 & 4 & 1.88 \\
\hline
\end{tabular}

that more thylakoid-bound precursor proteins were transported into the chloroplasts after HL stress.

\section{General stress}

Three enzymatic antioxidants were upregulated by 1.8to 7.8 -fold after $10 \mathrm{~h}$ of HL treatment, including chloroplastic peroxiredoxin $\mathrm{Q}$, thiol-disulfide isomerase and peptide methionine sulfoxide reductase (MsrA) (Table 2, Additional file 5: Table S3). In P. tricornutum, a peroxiredoxin $\mathrm{Q}$ gene was among the strongest and the most consistently upregulated genes during HL treatment [25]. It has been suggested that peroxiredoxin $\mathrm{Q}$ from A. thaliana was involved in the photosystem II protection against $\mathrm{H}_{2} \mathrm{O}_{2}$ [41]. Our study demonstrates that peroxiredoxin $\mathrm{Q}$ is vital for the normal growth of $T$. pseudonana in HL conditions on the ocean surface or during pool cultivation. The thiol-disulfide isomerase was first found in Emiliania huxleyi and is a novel selenoprotein, which is homologous to protein disulfide isomerase (PDI) and contains a highly conserved thioredoxin domain [42]. It is the second selenoprotein found in $T$. pseudonana in addition to sec-containing glutathione peroxidase [43]. MsrA catalyzes the reduction of methionine sulfoxide to methionine, which protects methionine in proteins from being oxidized [44]. Upregulation of MsrA suggests that MsrA plays an important role in protecting cellular proteins against photooxidation. Interestingly, we identified a high light induced protein 2 (ELIP) which was upregulated by 1.57 -fold after $10 \mathrm{~h}$ of HL stress. In higher plant, ELIPs belong to the family of light-harvesting complexes (LHCs), but they differ from the LHCs in response to HL stress. The LHCs bind chlorophyll and absorb solar energy and their expression is inhibited by HL. In contrast, ELIPs have been shown to be involved in photoprotection by binding chlorophyll released during turnover of LHCs or stabilizing LHCs during HL stress [45]. Our data confirmed the presence of ELIPs in marine diatoms.

Polypeptides will become misfolded or unfolded when cells are subjected to stress of adverse conditions. Heat shock proteins (HSP) can prevent misfolded proteins from aggregation in the cells and help them refold. Six HSP-related proteins were found to be upregulated significantly after $10 \mathrm{~h}$ of $\mathrm{HL}$ treatment, including chaperone protein dnaJ (CDnaJ), stress-inducible protein (STI1), heat shock protein DnaJ (HDnaJ), and co-chaperonin GroES (HSP10) (Table 2). STI1 functions as a co-chaperone which reversibly links HSP70 and HSP90 together and regulates the activities of the linked proteins [46]. In cyanobacteria and Arabidopsis, HL and $\mathrm{H}_{2} \mathrm{O}_{2}$, respectively, induced chaperones and HSPs [47], suggesting that certain HSPs are involved in protection function against oxidative conditions. Therefore, in T. pseudonana, the increased expression of HSP-related proteins may be an adaptable response to reduce the protein aggregation and misfolding caused by reactive oxygen species (ROS) during excess light treatment.

\section{Conclusions}

Using a quantitative proteomic approach based on iTRAQ labeling of peptides in combination with biochemical analyses, we studied the responses of diatoms to HL stress. We have demonstrated that light-harvesting complex, ROS scavenging systems, photorespiration/glyoxylate cycle, lipid metabolism and protein synthesis were involved in 
responses of diatoms to HL stress. Proteomic changes elicit a series of physiological changes in diatoms. Under HL stress, $\mathrm{Fv} / \mathrm{Fm}$ decreased and NPQ increased; the size of Dtx + Ddx pool increased; TAG increased and fatty acid composition was altered. Interestingly, certain specific proteins might fulfill a photoprotective function, including Lhcx6, Lhcx4, Lhcr8, Lhcr5, enzymatic antioxidants, ELIPs, and HSP-related proteins. These proteins protect diatom cells from photooxidation. In addition, marked upregulation of RDS probably suggests that other than the Dtx/Ddx cyle, the conversion of retinol to retinal may contribute to dissipation of excess light energy. These data will provide new insights into protection and acclimation strategies of diatoms in response to varying light conditions.

\section{Additional files}

Additional file 1: Table S1. Primers used in this study for $\mathrm{QRCR}$. (DOC $40 \mathrm{~kb}$ )

Additional file 2: Figure S1. Workflow for proteomic experiments using iTRAQ labeling in this study. T. pseudonana cells were acclimated in low light (LL) for 4 weeks and exposed to high light (HL) for $10 \mathrm{~h}$. Three biological replicates were performed. The extracted proteins were reduced, alkylated, and digested with trypsin after cell pellets were lysed. The tryptic peptides were then labeled with ITRAQ reagents and put together as shown. The SCX chromatography was performed to fractionate peptides and fractions were collected. The eluted peptides were analyzed by LC-MS/MS. (PPT $61 \mathrm{~kb}$ )

Additional file 3: Table S2. List of proteins identified with by MS/MS from the T. pseudonana extract with a minimum of 1 peptides at $>95 \%$ confidence in high light (HL)-treated experiment. (XLS $1082 \mathrm{~kb}$ )

Additional file 4: Figure S2. Error distribution (A, B, C, D, E, and F) among three biological replicates and CV distribution (G) between control and HL-treated samples. (DOC $250 \mathrm{~kb}$ )

Additional file 5: Table S3. The significantly differentially expressed proteins regulated by high light (HL) (Fold change $>1.5$ or $<0.67, P<0.05$ ). (XLS $72 \mathrm{~kb})$

\footnotetext{
Abbreviations

AMOS: Antibiotic biosynthesis monooxygenase; CA: Carbonic anhydrases; CCM: $\mathrm{CO}_{2}$-concentrating mechanisms; $\mathrm{CDnaJ}$ : Chaperone protein dnaJ; CEF: Cyclic electron flow; CFAPS: Cyclopropane-fatty-acyl-phospholipid synthase; Chl a: Chlorophyll a; COG: Cluster of orthologous groups; Ddx: Diadinoxanthin; DSP1: Death-specific protein; DTT: Dithiothreitol; Dtx: Diatoxanthin; ELIP: High light induced protein; ETR: Electron transport rate; FADS: Fatty acid desaturase; FAMEs: Fatty acid methyl esters; FCPs: Fucoxanthin Chl a/c proteins; FDR: False discovery rate; GO: Gene ontology; GOX: Glycolate oxidase; HL: High light; HPLC: High performance liquid chromatography; HSP: Heat shock proteins; IDA: Information-dependent acquisition; iTRAQ: Isobaric tags for relative and absolute quantification; LCFAL: Long-chain-fatty-acid-CoA ligase; LHC: Light-harvesting complex; LL: Low light; MsrA: Methionine sulfoxide reductase; NDSE: Nucleosidediphosphate-sugar epimerase; NPQ: Non-photochemical quenching; PDI: Protein disulfide isomerase; PEPCase: Phosphoenolpyruvate carboxylases; PEPCK: Phosphoenolpyruvate carboxykinase; PGK: Phosphoglycerate kinase; PKK: Phosphoribulokinase; PPDK: Pyruvate phosphate dikinase; PPOM: Peptidoglycan-associated outer membrane protein; PSII: Photosystem II; RDS: Retinol dehydrogenases; ROS: Reactive oxygen species;

Rubisco: Carboxylase/oxygenases; SRPS: Serine palmitoyltransferase; STI1: Stressinducible protein; TAG: Triacylglycerol; TEAB: Tetraethylammonium bicarbonate; VDL: Violaxanthin de-epoxidase-like; XC: Xanthophyll cycle
}

\section{Acknowledgements}

This study was funded by the Guangdong Natural Science Foundation (grant NO. 2015A030313326, S2013010013406), the National Natural Science Foundation of China (grant NO. 41576123, 41176087, 41206126), the Strategic Priority Research Program of the Chinese Academy of Sciences (XDA1 1020304), and General Financial Grant from the China Postdoctoral Science Foundation (Grant No. 2014 M562251).

\section{Availability of data and materials}

The data sets supporting the results of this study are included in the manuscript and its Additional files 1, 2, 3, 4 and 5.

\section{Authors' contributions}

HPD, YLD and SHL conceived and designed the study. YLD, LC and JG carried out the experiments. TJ performed the analysis of pigment data. HPD and SB wrote the manuscript. All authors and approved the final manuscript.

\section{Competing interests}

The authors declare that they have no competing interests.

\section{Consent for publication}

Not applicable.

\section{Ethics approval and consent to participate}

Not applicable.

\section{Author details}

${ }^{1}$ Research Center for Harmful Algae and Marine Biology, Key Laboratory of Eutrophication and Red Tide Prevention of Guangdong Higher Education Institutes, Jinan University, Guangzhou 510632, China. ${ }^{2}$ School of Ocean and Meteorology, Guangdong Ocean University, Zhanjiang 524088, China.

Received: 3 February 2016 Accepted: 17 November 2016

Published online: 05 December 2016

\section{References}

1. Armbrust EV. The life of diatoms in the world's oceans. Nature. 2009;459:185-92.

2. Tirichine L, Bowler C. Decoding algal genomes: tracing back the history of photosynthetic life on Earth. Plant J. 2011;66:45-57.

3. Riddle D. Feature article: imitating natural light quality, intensity, and dosage in a reef aquarium-do we really want to? http://www.advancedaquarist. com/2013/12/lighting. Accessed 18 Dec 2013.

4. Brunet C, Lavaud J. Can the xanthophyll cycle help extract the essence of the microalgal functional response to a variable light environment? J Plankton Res. 2010;32:1609-17.

5. Heber $U$, Bilger W, Shuvalov VA. Thermal energy dissipation in reaction centres and in the antenna of photosystem II protects desiccated poikilohydric mosses against photo-oxidation. J Exp Bot. 2006;57:2993-3006.

6. Ruban A, Johnson M. Dynamics of higher plant photosystem cross-section associated with state transitions. Photosynth Res. 2009;99:173-83.

7. Goss R, Jakob T. Regulation and function of xanthophyll cycle-dependent photoprotection in algae. Photosynth Res. 2010;106:103-22.

8. Schumann A, Goss R, Jakob T, Wilhelm C. Investigation of the quenching efficiency of diatoxanthin in cells of Phaeodactylum tricornutum (Bacillariophyceae) with different pool sizes of xanthophyll cycle pigments. Phycologia. 2007:46:113-7.

9. Lavaud J, Materna AC, Sturm S, Vugrinec S, Kroth PG. Silencing of the violaxanthin de-epoxidase gene in the diatom Phaeodactylum tricornutum reduces diatoxanthin synthesis and non-photochemical quenching. PLOS ONE. 2012;7:e36806

10. Kropuenske LR, Mills MM, van Dijken $G L$, et al. Strategies and rates of photoacclimation in two major southern ocean phytoplankton taxa: phaeocystis antarctic (Haptophyta) and fragilarriopsis cylindrus (Bacillariophyceae). J Phycol. 2010;46:1138-51.

11. Eisenstadt D, Ohad I, Keren N, Kaplan A. Changes in the photosynthetic reaction centre II in the diatom Phaeodactylum tricornutum result in nonphotochemical fluorescence quenching. Environ Microbiol. 2008;10:1997-2007.

12. Zhu SH, Green BR. Photoprotection in the diatom Thalassiosira pseudonana: Role of LI818-like proteins in response to high light stress. BBA-Bioenergetics. 2010;1797:1449-57. 
13. Domingues N, Matos AR, Marques da Silva J, Cartaxana P. Response of the diatom Phaeodactylum tricornutum to photooxidative stress resulting from high light exposure. PLoS ONE. 2012;7:e38162.

14. Lepetit B, Sturm S, Rogato A, et al. High light acclimation in the secondary plastids containing diatom Phaeodactylum tricornutum is triggered by the redox state of the plastoquinone pool. Plant Physiol. 2013;161:853-65.

15. Thamatrakoln K, Bailleul B, Brown CM, et al. Death-specific protein in a marine diatom regulates photosynthetic responses to iron and light availability. Proc Natl Acad Sci U S A. 2013;110:20123-8.

16. Carvalho RN, Lettieri T. Proteomic analysis of the marine diatom Thalassiosira pseudonana upon exposure to benzo(a)pyrene. BMC Genomics. 2011;12:159.

17. Hockin NL, Mock T, Mulholland F, Kopriva S, Malin G. The response of diatom central carbon metabolism to nitrogen starvation is different from that of green algae and higher plants. Plant Physiol. 2012;158:299-312.

18. Nunn BL, Faux JF, Hippmann AA, et al. Diatom proteomics reveals unique acclimation strategies to mitigate Fe limitation. PLOS ONE. 2013:8:e75653. doi:10.1371/journal.pone.0075653.

19. Berges JA, Franklin DJ, Harrison PJ. Evolution of an artificial seawater medium: improvements in enriched seawater, artificial water over the last two decades. J Phycol. 2001;37:1138-45.

20. Jakob T, Goss R, Wilhelm C. Activation of diadinoxanthin de-epoxidase due to a chiororespiratory proton gradient in the dark in the diatom Phaeodactylum tricornutum. Plant Biol. 1999;1:76-82.

21. Chen W, Zhang C, Song L, Sommerfeld M, Hu Q. A high throughput Nile red method for quantitative measurement of neutral lipids in microalgae. J Microbiol Methods. 2009;77:41-7.

22. Work VH, Radakovits $\mathrm{R}$, Jinkerson RE, et al. Increased lipid accumulation in the Chlamydomonas reinhardtii sta7-10 starchless isoamylase mutant and increased carbohydrate synthesis in complemented strains. Eukaryot Cell. 2010;9:1251-61.

23. The Thalassiosira pseudonana Database. http://www.ncbi.nlm.nih.gov/ Taxonomy/Browser/wwwtax.cgi?mode=|nfo\&id $=35128 \&|\mathrm{v}|=3 \&$ lin=f\&keep $=$ 1\&srchmode=1\&unlock. Accessed 29 Aug 2013.

24. Guenin S, Mauriat M, Pelloux J, et al. Normalization of qRT-PCR data: the necessity of adopting a systematic, experimental conditions-specific validation of references. J Exp Bot. 2009:60:487-93.

25. Nymark M, Valle KC, Brembu T, et al. An integrated analysis of molecular acclimation to high light in the marine diatom Phaeodactylum tricornutum PLOS ONE. 2009;4:e7743.

26. Norici A, Bazzoni AM, Pugnetti A, Raven JA, Giordano M. Impact of irradiance on the $C$ allocation in the coastal marine diatom Skeletonema marinoi Sarno and Zingone. Plant Cell Environ. 2011;34:1666-77.

27. Li X, Moellering ER, Liu B, et al. A galactoglycerolipid lipase is required for triacylglycerol accumulation and survival following nitrogen deprivation in Chlamydomonas reinhardtii. Plant Cell. 2012;24:4670-86.

28. Goodson C, Roth R, Wang ZT, Goodenough U. Structural correlates of cytoplasmic and chloroplast lipid body synthesis in Chlamydomonas reinhardtii and stimulation of lipid body production with acetate boost. Eukaryot Cell. 2011;10:1592-606.

29. Armbrust EV, Berges JA, Bowler C, et al. The Genome of the diatom Thalassiosira Pseudonana: ecology, evolution, and metabolism. Science. 2004;306:79-86.

30. Hopkinson $\mathrm{BM}$, Dupont $\mathrm{CL}$, Allen $\mathrm{AE}$, Morel FM. Efficiency of the $\mathrm{CO}_{2}-$ concentrating mechanism of diatoms. Proc Natl Acad Sci U S A. 2011:108:3830-7.

31. Kroth PG, Chiovitti A, Gruber A, et al. A model for carbohydrate metabolism in the diatom Phaeodactylum tricornutum deduced from comparative whole genome analysis. PLOS ONE. 2008;3:e1426.

32. Leboulanger $C$, Oriol $L$, Jupin $H$, Desolas-gros $C$. Diel variability of glycolate in the eastern tropical Atlantic Ocean. Deep Sea Res-PT I. 1997:44:2131-9.

33. Durkin CA, Mock T, Armbrust EV. Chitin in diatoms and its association with the cell wall. Eukaryot Cell. 2009;8:1038-50.

34. Smetacek VS. Role of sinking in diatom life-history cycles: ecological, evolutionary and geological significance. Mar Biol. 1985;84:239-51.

35. Hecky RE, Mopper K, Kilham P, Degens ET. The amino acid and sugar composition of diatom cell-walls. Mar Biol. 1973;19:323-31.

36. Fulda M, Shockey J, Werber M, Wolter FP, Heinz E. Two long-chain acyl-CoA synthetases from Arabidopsis thaliana involved in peroxisomal fatty acid B-oxidation. Plant J. 2002;32:93-103.
37. Li C, Wang Y, Liu L, et al. A rice plastidial nucleotide sugar epimerase is involved in galactolipid biosynthesis and improves photosynthetic efficiency. PLoS Genet. 2011;7:e1002196.

38. Sperling P, Heinz E. Plant sphingolipids: structural diversity, biosynthesis, first genes and functions. BBA-Mol Cell Biol L. 2003;1632:1-15.

39. Schellenberger Costa B, Jungandreas A, Jakob T, Weisheit W, Mittag M, Wilhelm C. Blue light is essential for high light acclimation and photoprotection in the diatom Phaeodactylum tricornutum. J Exp Bot. 2013;64:483-93.

40. Cline $\mathrm{K}$, Mori $\mathrm{H}$. Thylakoid $\Delta \mathrm{pH}$-dependent precursor proteins bind to a cpTatC-Hcf106 complex before Tha4-dependent transport. J Cell Biol. 2001:154:719-30.

41. Lamkemeyer P, Laxa M, Collin V, et al. Peroxiredoxin Q of Arabidopsis thaliana is attached to the thylakoids and functions in context of photosynthesis. Plant J. 2006:45:968-81.

42. Araie $H$, Suzuki I, Shiraiwa $Y$. Identification and characterization of a selenoprotein, thioredoxin reductase, in a unicellular marine haptophyte alga, Emiliania huxleyi. J Biol Chem. 2008;283:35329-36.

43. Obata T, Araie H, Shiraiwa Y. Bioconcentration mechanism of selenium by a coccolithophorid, Emiliania huxleyi. Plant Cell Physiol. 2004;45:1434-41.

44. Weissbach $\mathrm{H}$, Etienne $\mathrm{F}$, Hoshi $\mathrm{T}$, et al. Peptide methionine sulfoxide reductase: structure, mechanism of action, and biological function. Arch Biochem Biophys. 2002:397:172-8.

45. Hutin C, Nussaume L, Moise N, Moya I, Kloppstech K, Havaux M. Early light-induced proteins protect Arabidopsis from photooxidative stress. Proc Natl Acad Sci U S A. 2003;15:4921-6.

46. Odunuga OO, Longshaw VM, Blatch GL. Hop: more than an Hsp70/Hsp90 adaptor protein. BioEssays. 2004;26:1058-68.

47. Hihara Y, Kamei A, Kanehisa M, Kaplan A, Ikeuchi M. DNA microarray analysis of cyanobacterial gene expression during acclimation to high light. Plant Cell. 2001;13:793-806.

\section{Submit your next manuscript to BioMed Central and we will help you at every step:}

- We accept pre-submission inquiries

- Our selector tool helps you to find the most relevant journal

- We provide round the clock customer support

- Convenient online submission

- Thorough peer review

- Inclusion in PubMed and all major indexing services

- Maximum visibility for your research

Submit your manuscript at www.biomedcentral.com/submit

) Biomed Central 